\title{
LA QUIMERA EN LA QUIMERA DE LORCA: UN ESTUDIO DE RECEPCIÓN
}

\section{THE CHIMERA IN LORCA'S CHIMERA; A RECEPTION STUDY}

\section{Cristina FILÍMONOS}

Universidad Complutense de Madrid chrisfil@ucm.es

Resumen: Quimera es uno de los diálogos breves del tríptico dramático de Federico García Lorca Diálogos. La Quimera es, en la mitología clásica, un monstruo híbrido, no obstante, a lo largo del tiempo la palabra "quimera" adquiere también el significado metafórico del deseo de lo imposible, la ilusión. El objetivo de este trabajo es averiguar cómo se relaciona el título de la obra con su contenido, así como hasta qué punto se refiere al monstruo mitológico o al significado abstracto derivado de éste. En primer lugar, se hace un análisis de las características del monstruo que se podrían aplicar al elemento femenino de este drama, junto con otros ecos clásicos que se aprecian en la obra. En segundo lugar, se examinan las quimeras, es decir, los deseos irrealizables, que angustian a toda la familia del diálogo. Se hace, así, un estudio de la recepción de la figura y las características de la Quimera en una de las obras teatrales lorquianas y se pretende identificar una acepción de la palabra que se refiere al mismo tiempo tanto a su significado mitológico como al metafórico.

Palabras clave: Federico García Lorca, simbolismo, mitología griega, Quimera, tradición clásica.

Abstract: Chimera is one of the Federico García Lorca's three brief dramatic Dialogues. Chimera, in classical mythology, is a hybrid monster, however, over time the word "chimera" acquires another, metaphorical meaning, that of the desire of the impossible, the illusion. The aim of this paper is to uncover how the play's title is connected to its essence, as well as whether it refers to the mythological monster or the secondary, abstract meaning. Firstly, the monster's characteristics that could be applied to the feminine element of the play are analysed, as well as the rest of the classical references featured throughout the dialogue. Then, the chimeras, in other words, the impossible, unreachable desires that distress the play's entire family are examined. In that way, the chimeric figure's and characteristics' reception are studied in one of Lorca's theatrical plays and what is 
74 | Tropelías. Revista de Teoría de la Literatura y Literatura Comparada, 33 (2020) Cristina Filímonos

intended to be established is a meaning of the word which includes both the mythological and the metaphorical sense.

Key-words: Federico García Lorca, symbolism, Greek mythology, Chimera, classical tradition. 


\section{1}

\section{Objetivo-Metodología}

Quimera es un diálogo dramático breve de Federico García Lorca ${ }^{1}$. El objetivo de este trabajo es averiguar cómo se relaciona el título de la obra con su contenido, así como hasta qué punto se refiere al monstruo mitológico o al significado abstracto derivado de éste. Después de una introducción tanto a la obra, a la figura mitológica y al significado metafórico de la Quimera, como al uso, por parte de Lorca, de la imagen y la metáfora mitológicas, se hace, por un lado, un análisis comparativo entre las características del monstruo y las del personaje Mujer y un estudio de los demás rasgos clásicos del drama y, por otro, un estudio de los deseos quiméricos de los personajes. Se pretende establecer así la acepción que da Lorca a la Quimera, tal vez muy personal, que otorga el mismo peso a los dos significados y se centra en el elemento femenino en general, más concretamente en el personaje Mujer.

\section{Introducción}

\section{1. El drama Quimera}

Junto con El paseo de Buster Keaton y La doncella, el marinero y el estudiante, Quimera estaba destinada a la revista granadina Gallo. No obstante, el número de la revista donde aparecía la obra en cuestión no fue publicado. El tríptico Diálogos, que el poeta escribe a partir del 1925 y probablemente concluye en 1928, abre, de algún modo, el ciclo del "teatro imposible" (García-Posada, 2004: 9-10). Escritos en prosa, experimentales y de atmósfera surrealista, los Diálogos fueron caracterizados por el poeta como "extraños" y "poesía pura”. Corresponden a la definición del teatro del propio Lorca: "el teatro es la poesía que se levanta del libro y se hace humana" (García-Posada, 2008c: 12-13; Turel, 1986: 351).

Quimera es una obra breve, de una escena y cuatro personajes, un Hombre, un Viejo, una Mujer y una Niña. Desde el interior de la casa, como voces fuera de la escena, se escuchan más niños. Las únicas informaciones escénicas y espaciales que tenemos son la mención de una puerta y una ventana, límites de la división del espacio en el interior y el exterior. El núcleo de la obra es la partida y la despedida del padre, en el exterior de la casa, a quien los hijos hacen peticiones. Solo uno de los hijos, la Niña, aparece en la escena, para cambiar varias veces de opinión sobre su petición. Delante de la casa un Viejo mendigo se ofrece para cargar las maletas del Hombre, mientras aquél habla sobre su pasado y el de la Mujer. Ella se despide de su marido por la ventana, expresando su sentimiento de soledad y el violento deseo erótico que él le provoca. Las últimas palabras de la obra son las de la Niña, que pide, rompiendo a llorar, el encargo inicial.

\footnotetext{
${ }^{1}$ Citaremos el texto a partir de la edición de Miguel García-Posada (2004).
} 


\section{2. El monstruo mitológico}

En la mitología clásica la Quimera es un monstruo híbrido, con cabeza y cuerpo de león, otra cabeza de cabra saliendo del lomo y la parte trasera de serpiente (Homero, Iliada, 6.179-182, 16.328329; Hesíodo, Teogonía, 319-325). Enorme y fuerte, destruía la tierra y a los hombres exhalando fuego, característica esta que la hacía invencible; no pertenecía al linaje humano, sino al divino. A pesar de su aparente inmortalidad, Belerofonte logró darle muerte, por orden del rey de Licia Yóbates. Montado en el caballo alado Pegaso, le disparó flechas, cuyas puntas llevaban plomo, hasta que acertó en su boca. El aliento ardiente del monstruo derritió el plomo y provocó su muerte (Graves, 1955: 252-256; Grimal, 2010, s.v. Quimera; Graziosi y Haubold, 2010: 120-35).

\section{3. El significado moderno de "quimera"}

El trayecto del uso de este ser híbrido ha sido largo y la adquisición de valor simbólico tiene que ver con la mentalidad, el pensamiento y la filosofía de cada época y sociedad. En genética, por ejemplo, "quimera" es el nombre del ser vivo que tiene dos o más poblaciones de células genéticamente distintas que se originaron en diferentes cigotos. Pero el uso más extendido de este término es el metafórico, refiriéndose a una fantasía, una utopía, una ilusión. De hecho, se trata de una creación imaginaria que un individuo fabrica en su mente, una utopía que es imposible de conseguir, pero que el sujeto en cuestión considera real. De ahí las expresiones "ser una quimera", "vive de quimeras" o "perseguir quimeras", refiriéndose a fantasías que uno cree que alcanzará.

\section{Lorca y la metáfora mitológica}

¿A cuál de los dos significados de la "quimera" se refiere Lorca: al metafórico o al mitológico? Lo más probable es que a ambos ${ }^{2}$, extraídos por el poeta de la tradición y la recepción en una manera directa e indirecta al mismo tiempo. En su poesía dramática y su teatro poético, ya que lo dramático fue siempre lo que más le interesaba, pero en su dimensión poética, expresa continuamente su visión del mundo como un espacio donde todo se conecta y todo puede tener connotaciones. En sus textos, personas, animales, naturaleza, objetos, ideas y sentimientos (es decir, elementos concretos o más abstractos) ofrecen lecturas en múltiples niveles (Cristóbal, 1993: 377-379). Herramientas básicas para esta característica de su arte eran la imagen y la metáfora, que manejaba de manera extraordinaria. Las imágenes y las metáforas poéticas le permitieron experimentar con los giros semánticos y crear un mundo simbólico y dinámico, lleno de vida y perfectamente equilibrado entre lo que es lírico y lo que es dramático, lo onírico, lo fantástico y lo realista. Él mismo definió la imagen como "un cambio de trajes, fines u oficios entre objetos o ideas de la Naturaleza" y de la metáfora dijo que "une dos mundos antagónicos por medio de un salto ecuestre que da la imaginación" (García-Posada, 2008a: 67; Cristóbal, 1993: 378).

\footnotetext{
${ }^{2}$ Esta interpretación fue expresada ya por Sarah Turel en su artículo citado, fundamental para el estudio de esta obra.
} 
El mito clásico le abrió un mundo infinito de imágenes y metáforas. Mucho debate ha habido las últimas décadas en torno al nivel de conocimiento y de lectura por parte de Lorca de los autores clásicos. Incluso en vida, se cuestionaba el nivel de cultura literaria que tenía Lorca en general, no solo en lo que atañe a la literatura antigua. Sin embargo, testimonios como los de su hermano, Francisco García Lorca, y de amigos suyos como Rafael Martínez Nadal, Luis Sáenz de la Calzada o Ana María Dalí, entre otros, dan fe de que el autor conocía muy bien, aparte de los autores españoles del Siglo de Oro, a muchos autores antiguos griegos y latinos (Camacho, 1990: 55-57; Aguilar, 1998: 76-78) . Había leído las Metamorfosis de Ovidio, que mencionan la Quimera (Ovidio, Metamorfosis, 9.646-8), y tenía incluso como libro de cabecera una edición bilingüe de la Teogonía de Hesíodo, dato que resulta de interés especial para este trabajo, ya que en la Teogonía y en la Iliada es donde la Quimera aparece por primera vez. A lo largo de su obra, Lorca muestra rasgos afectados por su "devoción por Hesíodo" (Aguilar, 1998: 98).

Parece, entonces, que estaba especialmente familiarizado con la mitología griega y su característica atemporal. Los mitos griegos, como todos los mitos, superan el tiempo y la realidad, parten de una red de narraciones de un pasado lejano, tienen varias funciones en distintas épocas y contextos, llaman a ser interpretados a múltiples niveles y forman parte de un sistema semiótico complejo. Se desarrollan sobre una base diacrónica, a pesar de sus posibles aspectos sincrónicos y a través de su función simbólica, que une lo individual a lo colectivo, lo consciente a lo inconsciente (Arango, 2007: 160-1, 170). A este carácter arcaico de la mitología, y vinculado a la psicología y al espíritu colectivo, se debe su abstracción. En el mito lo que importa es el contenido y la historia, mientras que en la poesía es la palabra. Lorca enlaza estos dos elementos de forma muy original y extrapolándolos a contexto andaluz, de manera constante en su poesía. En una carta suya de 1923 dejó saber a un amigo que estaba haciendo "interpretaciones modernas de figuras de la mitología griega" (Camacho, 1990: 61). El poeta granadino interioriza el mito clásico y lo traslada a la actualidad, revitalizándolo (Aguilar, 1998: 100). A veces la referencia es tan sutil o indirecta que se requiere mucho estudio para ser percibida. En su obra dramática es donde más relación con el mito clásico se aprecia, mientras que sus tragedias se caracterizan por los valores y el ambiente, así como por el “espíritu”, de la tragedia griega clásica (Camacho, 1990: 69-72).

Una figura mitológica que conlleva múltiples acepciones ya desde la Antigüedad, como es la Quimera, no podría faltar en el universo lorquiano. Su naturaleza monstruosa y marginal, por un lado, y la connotación abstracta del deseo irrealizable que adquirió a lo largo del tiempo, por otro, encajan con la estructura irracionalista de la imagen y la metáfora de Lorca ${ }^{6}$. Además, como se analizará a continuación, a través de la doble acepción de la figura en cuestión se refleja la dualidad y la conexión estrecha entre contrarios, tan común en su obra (García-Posada, 2008a: 59).

\footnotetext{
${ }^{3}$ Para más información sobre este tema, véase, por ejemplo, Martínez Nadal (1986: 38-49).

${ }^{4}$ Sobre la influencia de Hesíodo en la obra juvenil lorquiana véase Agoglossakis (2012).

${ }^{5}$ Sobre la influencia de la tragedia griega, ante todo la de Eurípides, en el drama lorquiano véase Carmona (2003).

${ }^{6}$ Sobre la estructura irracionalista de la imagen lorquiana véase Cristóbal (1993: 378).
} 


\section{Rasgos clásicos en la obra}

¿Cómo se desarrollan el simbolismo y la metáfora mitológica en el diálogo Quimera? Se hará, en primer lugar, una interpretación del título de la obra a partir del primer uso de la palabra "quimera", como nombre de la figura mitológica. La Quimera que da nombre al título no aparece de manera explícita a lo largo del diálogo. Al aparecer en primer término provoca ciertas expectativas en el lector, al mismo tiempo que le incita a encontrarse ante un contexto muy definido y a buscar paralelismos entre el mito y la obra (Bermúdez, 2013: 13-4). Además, otros elementos clásicos, aparte del mito en cuestión, aparecen en el diálogo.

Más concretamente, al leer la obra se puede hacer la conexión entre el terrible monstruo híbrido y la Mujer, terrible también (Turel, 1986: 352-358) ${ }^{7}$. La protagonista parece recibir las cualidades del referente mitológico. Cuando dice "Te veo pequeño. Saltas por las piedras. Pequeño. Ahora te podría tragar como si fueras un botón. Te podría tragar, Enrique..." nos hallamos ante el tema de la muerte del hombre por la mujer y del amor como sinónimo de muerte, temas nucleares de la obra de Lorca (García-Posada, 2008a: 44, 47-49) ${ }^{8}$. De especial interés resulta la elección del verbo "tragar", que alude a la acción salvaje de un ser como la Quimera, mortífera e invencible ${ }^{9}$. Es más, la relación de los seres híbridos con la muerte es muy estrecha, ya que la ambigüedad y la marginalidad de su naturaleza los coloca en la transición entre la vida y la muerte, como se verá más adelante. Por otro lado, la muerte del hombre por el elemento femenino, desconocido y peligroso, los monstruos femeninos, era en la literatura griega un factor muy recurrente: la Medusa petrifica, la Esfinge rapta, la Quimera destruye con fuego o, en este contexto, "traga". Por lo tanto, la analogía entre la Mujer y la Quimera en un contexto morboso y peligroso parece más que oportuna.

La madre, que está dentro de la casa, aparece como una matriarca autoritaria, cuando la vemos, por ejemplo, reteniendo a la Niña, para que no salga de casa -"No salgas. Se ha levantado un viento frío. ¡He dicho que no!”-, mientras que hacia su marido expresa una sexualidad agresiva y desenfrenada, que amplifica su sentimiento de soledad y desesperación:

Yo en cambio estaré sola en la cama. Tendré frío. Él tiene unos ojos maravillosos; pero lo que yo amo es su fuerza. (Se desnuda.) Me duele un poco la espalda. ¡Ah! ¡Si me pudiera despreciar! Yo quiero que él me desprecie... y me ame. Yo quiero huir y que me alcance. Yo quiero que me queme... que me queme.

Su discurso, vivo y dinámico, es el más largo del diálogo; la Mujer está en el epicentro. Sin embargo, ella carece de nombre, al contrario que Enrique. Sus palabras son casi incoherentes, no queda claro ni siquiera su estado anímico. El Viejo la considera afortunada - "Ella es feliz"-, pero no es nada más que el pasado del que habla él, que está en contraste con el presente agobiante de la Mujer. Ella se encuentra en un estado de frustración amorosa y represión sexual, que se analizará más adelante.

\footnotetext{
${ }^{7}$ Cf. Luna y panorama de los insectos 21: “Tú Madre siempre terrible”, que ya subraya Turel.

${ }^{8}$ Cf. el prólogo de El maleficio de la mariposa: "la Muerte se disfraza de Amor".

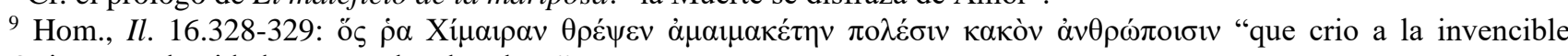
Quimera, calamidad para muchos hombres".
} 
Igual que la Mujer, la Niña es la única, de los hijos, que toma la palabra, pero tampoco se le da nombre. Además, sus frases parecen confusas y contradictorias, de modo que resulta ignorada por su padre. Las palabras del elemento femenino en Quimera recuerdan a las del drama griego ${ }^{10}$ : no promueven el avance del diálogo, como las de los hombres, son menos frecuentes, poco coherentes y resultan enigmáticas para los hombres. Es este uno de los aspectos de la percepción del elemento femenino como algo incomprensible y peligroso, tan presente en las obras lorquianas como en el mundo clásico. Como notó Bremmer, mientras hoy en día los peligros graves aparecen como amenazas extraterrestres, en la Antigüedad tenían forma femenina (Bremmer, 1987: 46). La mujer y los monstruos, que son en gran mayoría femeninos ${ }^{11}$, causan una ansiedad profunda, pues combinan las dos fuentes de miedo más básicas para la sociedad patriarcal; el miedo a lo femenino como lo otro y el miedo a la muerte. Los dos elementos forman parte del miedo del hombre a lo desconocido. La mujer, el elemento femenino en general, símbolo de la naturaleza, es peligrosa e imprevisible, lo que forma un riesgo serio para el equilibrio de la civilización del hombre (Bernabé, 2008: 172-3). Lo desconocido, el elemento imaginario de lo monstruoso como expresión de desorden, la asociación con el destino y la muerte, se relacionan a menudo en la mitología con las mujeres "como encarnación de los males" (Rodríguez, 2011: 65-7).

En Lorca este miedo a la mujer se describe de manera viva y simbólica. Le interesa el mundo psicológico de la mujer y la interacción entre los dos sexos. La mujer es la protagonista real de sus obras y la protagonista de Quimera. De ahí que la relación del contenido del diálogo parezca cada vez más estrecha con su título. Lorca presenta la condición femenina desde el punto de vista femenino, en un contexto oscuro, un cuadro surrealista, mientras que caracteriza a la mujer, por otro lado, desde el punto de vista de la sociedad poco empática: un ser complejo y peligroso. El Hombre, Enrique, fracasa en entenderlas a ambas, a la Mujer y a la Niña, y en conectar con su familia, mientras que su partida, su alejamiento físico de la casa, parece ser la solución al alejamiento emocional que ya se puede notar en el diálogo entre el elemento femenino y el masculino. Se aleja de la Mujer que eventualmente lo podría "tragar" (Turel, 1986: 355).

La división espacial en el interior y el exterior de la casa principalmente subraya la distancia entre los hombres del diálogo y la Mujer con los niños. Sin embargo, en una segunda lectura, la casa se puede percibir no solo como un espacio interior, sino también, dentro del contexto surrealista, como un sitio oscuro y misterioso, lleno de voces indistinguibles. Como ya se ha comentado, la casa también resulta un lugar hasta peligroso para el Hombre, ya que la figura central de la casa es la Mujer, cuyo amor por él lo conduciría finalmente a su muerte. Asimismo, y analizando un poco más el paralelismo entre la Mujer y la Quimera mitológica, la casa parece ser un símbolo ideal del lugar que habitan los monstruos. Más concretamente, los seres híbridos, monstruosos, ambiguos, marginales, en su sentido

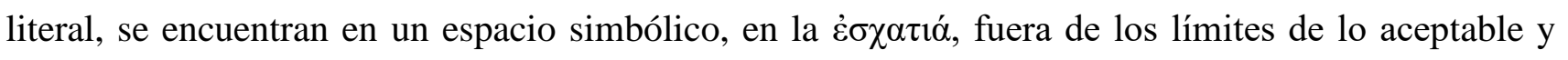
conocido, de la sociedad, entre la realidad y la imaginación (Cabrera, 2012: 13-4, 47-8; González y

\footnotetext{
${ }^{10}$ Sobre la voz femenina en la literatura y el contexto social griego véase Iriarte (1990).

${ }^{11}$ Al respecto véase González Terriza (2015), ante todo el Estudio comparativo (1177-1349).
} 
Porres, 2012: 227) ${ }^{12}$. Esos lugares son análogos al uso mitológico, simbólico y cultural de los monstruos híbridos; causan miedo y amenazan, imponen la necesidad de la distancia, a la par que parecen misteriosos, peligrosos e inexplicables, sinónimos de la muerte e intermediarios entre la vida y la muerte, "el reino de la alteridad por excelencia" (Cabrera, 2012: 14).

En cuanto al último personaje de la obra, el Viejo, es posible que sea una proyección de Crono (Xpóvos) (García-Posada, 2008a: 83), del tiempo que lleva a Enrique más cerca de la muerte, una especie de Caronte griego. Su vínculo con la muerte se expresa, por ejemplo, a lo largo de la obra a través de su miedo a los caballos, símbolo de la vida muy presente en el mundo lorquiano (Turel, 1986: 354-5). Es posible, no obstante, que no se restrinja el Viejo a ser el acompañante macabro de Enrique, sino que desempeñe también el papel de lo que sería el coro griego. En primer lugar, como se ha mencionado, su conversación con Enrique, el antagonista de la obra, cumple la función del avance del diálogo. Además, hace comentarios sobre todos los miembros de la familia, da información necesaria para la comprensión del contexto de la obra, datos del pasado de la Mujer, da su opinión y consejos al Hombre. Parece probable que sea él la personificación de una interpretación lorquiana del coro, muy personal y muy especial en esta obra, como pasa en muchas otras obras suyas ${ }^{13}$. Este es un dato procedente del teatro clásico, así como el número reducido de personajes o el hecho de que el diálogo forma parte de un tríptico, como las trilogías griegas.

Finalmente, respecto a las peticiones de los niños, que al principio son tres, provienen del mundo animal: una ardilla, un lagarto y un topo ${ }^{14}$. El número tres es característico del cuento popular, del que Lorca era gran conocedor. De todas formas, la analogía entre los tres animales y el número de partes de las que consta el cuerpo de la Quimera mitológica es evidente. La elección de esos animales específicos es interesante: el lagarto es un reptil, y la cola de la Quimera es una serpiente. Hasta aquí el paralelismo parece posible. El lagarto no tiene las acepciones negativas que conlleva la serpiente, que puede simbolizar, entre otras cosas, el mal, la traición y la muerte; en la poesía de Lorca aparece como un animal bajo ${ }^{15}$. El lagarto, animal pasivo, junto con el topo, animal lento, se utilizan en contraste con la ardilla, que es alegre e inquieta y simboliza la vitalidad. Es por la que la Niña opta al final de la obra (Turel, 1986: 357).

Después de los animales, la siguiente petición de los niños, "una colección de minerales", también encuentra su analogía con el ser mitológico. Los minerales tienen valor de muerte en la obra lorquiana. Aquí puede que lo tengan incluso más, ya que según el mito de la Quimera y Belerofonte, el héroe la mató acertando con una flecha de plomo en su boca. Probablemente haya alguna analogía entre la referencia de los minerales y la causa de la muerte del ser híbrido, teoría que se refuerza por

\footnotetext{
${ }^{12}$ Los seres híbridos no pertenecen al mundo de los hombres en la mitología griega, pero tampoco al de los dioses. Según Homero, la Quimera sí que "era de generación divina”, sin embargo Belerofonte le dio muerte. Es esta otra prueba de que los seres híbridos se encuentran en el margen y simbolizan la transición entre la vida y la muerte.

${ }^{13}$ Sobre la presencia del coro en la obra lorquiana véase, por ejemplo, Carmona (2003: 59-71).

${ }^{14}$ Como dato curioso se puede mencionar un posible juego de palabras entre ardilla, lagarto y topo; el "lagarto" tiene elementos silábicos que se repiten en las palabras anterior y posterior, dando un resultado fonético parecido.

${ }^{15} \mathrm{Cf}$. Así que pasen cinco años, Acto primero: “GATA. ¿Qué pasa? NIÑO. Vienen a comernos. GATA. ¿Quién? NIÑO. El lagarto y la lagarta, con sus hijitos pequeños, que son muchos”.
} 
la afirmación de la Niña de que no quería los minerales porque "le romperán las uñas". Así pues, a través de los pedidos de los niños surgen indirectamente más datos para la conexión con el mito.

\section{Deseos quiméricos en el diálogo}

La segunda metáfora que se reconoce en el diálogo es el propio significado metafórico del nombre abstracto "quimera"16. La figura mitológica de la Quimera se intentó interpretar desde época muy temprana, dado que resultaba un fenómeno curioso para los autores, porque de los seres híbridos era de los más difíciles; no combinaba dos, sino tres elementos distintos, hecho que no era muy común, incluso en el mundo de los monstruos. De hecho, era el colmo de la complejidad. El generalizado y primitivo miedo a los animales vinculado con el miedo a lo femenino como "lo otro", dieron como resultado la compleja y misteriosa Quimera. Como epítome de la imposibilidad, no tardó en significar lo imposible de existir, la ilusión ${ }^{17}$.

La Quimera, a través de toda esta imposibilidad, traduce una angustia, y la angustia es el deseo en su forma negativa. La frustración, el deseo de lo que no puede ser o que no se puede especificar, las situaciones emocionales y existenciales sin salida y la insatisfacción están presentes en toda la obra de Lorca (Román, 2003: 401-2; Turel, 1986: 357). Se expresan de maneras muy distintas, pero se puede decir que se centran en dos líneas principales: la frustración por razones ontológicas y la frustración por causa del impacto social (García-Posada, 2008a: 41-2). En el diálogo Quimera estos sentimientos agobiantes se comparten entre toda la familia.

Inquietud y confusión sentimental, por ejemplo, sufre Enrique, pues por un lado tiene prisa y siente frustración por la detención por parte del Viejo y de sus hijos, no obstante parece sentirse excluido de la vida de la casa y triste por su partida -“me pesa esta ausencia"-(Turel, 1986: 354). Él se aleja emocionalmente y físicamente de su familia, pero principalmente de su mujer, en consecuencia de "la pasión amorosa que se va a extinguir en medio o a causa de la trivialidad" (García-Posada, 2004: 10). La idealización del pasado de las vidas de la pareja se manifiesta en sus palabras:

VIEJO. [...] ¿Te acuerdas cómo saltaba las tapias, como se subía a los árboles sólo por verte? MUJER. Lo recordaré hasta que me muera.

ENRIQUE. Yo también.

En segundo lugar y en el caso de los hijos nos hallamos ante la imposibilidad de definir el objeto del deseo. Desde luego este tipo de frustración es expresada mejor por la Niña, que es la que más intensamente expresa sus encargos y se agobia por sus propios cambios de opinión, así como por no

\footnotetext{
${ }^{16}$ Véase, por ejemplo, el uso de "quimera" en otra obra de Lorca, Mariana Pineda, donde la palabra se utiliza solo con su sentido metafórico, como lo que es imposible de conseguir, lo irrealizable, lo utópico: "No es hora de pensar en quimeras, que es hora / de abrir el pecho a bellas realidades cercanas..." (estampa segunda).

${ }^{17}$ Cf. Borges (1967, s.v. Quimera): "Estas conjeturas absurdas prueban que la Quimera ya estaba cansando a la gente. Mejor que imaginarla era traducirla en cualquier otra cosa. Era demasiado heterogénea; el león, la cabra y la serpiente (en algunos textos, el dragón) se resistían a formar un solo animal. Con el tiempo, la Quimera tiende a ser lo 'quimérico'; [...] La incoherente forma desaparece y la palabra queda, para significar lo imposible".

De todas formas, como se ha dicho antes, la evolución del uso y simbolismo de la Quimera no ha sido en absoluto sencilla, sino larga y de varios parámetros, que no son el objetivo de este trabajo.
} 
conseguir ser escuchada. Presenta un conflicto interno (Turel, 1986: 355-358). El estado sentimental de la Niña se podría traducir como la reacción al primer contacto con su restricción en el interior, marcado por la puerta y la ventana, y la distancia física y psicológica, literal y metafóricamente, entre los dos sexos. Intenta salir de casa, de su "lugar apropiado", hasta que se lo impide su madre. El comportamiento de la Niña expresa la inquietud causada por la represión social, que sufren los caracteres femeninos lorquianos (García-Posada, 2008a: 44-45) ${ }^{18}$.

La Mujer de Quimera, desde luego, es la que principalmente se encuentra en este estado anímico. Parece tener bastante asumida su posición en la casa, sin escapatoria. Se tortura por su aparente debilidad, por su pasado idealizado perdido, mientras que sigue siendo poderosa, la que puede aniquilar al Hombre como la Quimera. Este díptico tan contradictorio dentro del personaje de la Mujer recuerda otra acepción de la palabra "quimera", que se utiliza metafóricamente incluso hoy en día en biología, la de un organismo compuesto de partes heterogéneas. Por un lado, es una mujer fuerte, por otro, se halla privada de sus fuerzas en el espacio interior. Por un lado, ama a Enrique vehementemente, por otro, lo quiere "tragar como si fuera un botón”. La conexión entre contrarios, como los que enseña la Mujer, es un tema recurrente en Lorca y una fuente de la frustración de sus caracteres. Al mismo tiempo, la pasión violenta de la protagonista por Enrique se convierte en otra quimera para ella, en algo imposible e inalcanzable. El amor total en Lorca es imposible, una ilusión (García-Posada, 2004: 12). La Mujer padece tanto de frustración amorosa y sexual, por la imposibilidad de conseguir el amor ideal con Enrique, como de frustración a causa de la represión, sobre su lugar y papel apropiados, que la sociedad le impone. A su vez, las quimeras que angustian a la Mujer la convierten a ella misma en una Quimera terrible y devoradora. El amor irrealizable así resulta sinónimo de muerte.

La escena se desarrolla en el exterior, fuera de la casa, donde se hallan los hombres (Turel, 1986: 352-353), sin embargo, parece que lo que a Lorca le interesa se encuentra dentro de ella. Mientras las palabras de los hombres son las que sirven para avanzar el diálogo, las emociones y los pensamientos de la Mujer son de importancia crucial para descifrar el misterio de la obra y de su título, de manera que, al menos brevemente, a lo largo de este trabajo, durante toda la lectura, hemos tratado de estar al lado de la ventana, junto a ella.

\section{Conclusiones}

A modo de conclusión, y en las palabras de Victor Hugo: "la palabra quimera tiene dos sentidos, significa sueño y significa monstruo. ¡Cuánto se paga por ilusos!”19. El título del diálogo breve Quimera se conecta armónicamente con su contenido abstracto y oscuro, mientras que la polisemia de la palabra prepara al receptor para lecturas profundas en distintos niveles. El simbolismo en toda la obra, o bien basado en la mitología o bien en su recepción, en el propio ser monstruoso o sus acepciones posteriores, resulta vivo y dinámico. Por un lado, en el caso de la metáfora del monstruo en el personaje

${ }^{18}$ Cf. Bodas de sangre, Acto segundo, Cuadro segundo: "MADRE. Mientras una vive, lucha.".

19 "Le mot chimère a deux sens, il signifie rêve, et il signifie monstre. Comme on se paye de billevesées!", en Hugo (1976: $3,7,1)$. 
de la Mujer, se puede reconocer que ella recibe algunas cualidades de la Quimera, que se refuerzan por el uso de palabras como el verbo "tragar". Otros rasgos del diálogo, como el estado anímico y social del elemento femenino en la obra parecido al de la literatura griega, la afinidad de la casa aislada y oscura a los lugares que habitan los monstruos, las funciones del personaje Viejo parecidas a las de un Caronte o el coro de un drama griego, la analogía entre los animales que piden los niños y las tres partes de la Quimera, tanto como la analogía entre los minerales y el plomo que mató a la Quimera, hacen que consten más referencias clásicas en la obra. Por otro lado, los enigmáticos personajes expresan ansiedades y sentimientos por lo que no pueden conseguir o por deseos que no pueden especificar, que corresponden al significado más moderno de la palabra “quimera". La Mujer está en el epicentro, se atormenta por un amor feroz, que lleva a la muerte, no puede ser entendida, salvo por el poeta, y junto con él, por nosotros. Federico García Lorca, creador de un mundo entero de imágenes y metáforas mitológicas, elige un símbolo que presenta innatas distintas funciones e interpretaciones y consigue llegar a su propia acepción de la palabra, que se refiere tanto a la figura mitológica como al significado abstracto, mediante el personaje de una mujer, que, angustiada por sus quimeras, se convierte ella misma en una.

\section{Bibliografía}

Aguilar Fernández, R. M. (1998). El mito griego en la poesía de García Lorca. Cuadernos de Filología Clásica (Estudios griegos e indoeuropeos), 8, 75-102.

Agoglossakis, S. (2012). Hesíodo y la poesía juvenil de Federico García Lorca. En P. BotTA (Coord.), Rumbos del hispanismo en el umbral del Cincuentenario de la AIH, vol. V, Moderna y Contemporánea (eds. L. Silvestri, L. Frattale, y M. Lefèvre) (pp. 152-159). Roma: Bagatto Libri. Arango, M. A. (2007). Presencia mítica de las culturas arcaicas en la obra de Federico García Lorca. Pensamiento y Cultura, 10 (1), 159-171.

Bermúdez RAMiro, J. (2013). Figuras mitológicas y personajes del mundo clásico en la poesía de García Lorca. Fundamentos y procedimientos creativos. Cultura, lenguaje y representación, 11, 9-28.

Bernabé PAJARES, A. (2008). Dioses, héroes y orígenes del mundo: lecturas de mitología. Madrid: Abada.

Borges, J. L. (1967). El libro de los seres imaginarios. Buenos Aires: Kier.

BREMMER, J. (1987). Interpretations of Greek mythology. London: Croom Helm.

CABrera, P. (2012). Los seres híbridos: imágenes de la alteridad en la Grecia Clásica. En A. BERNABÉ PAJARES y J. PÉREZ de Tudela (Eds.), Seres híbridos en la mitología griega (pp. 13-48). Madrid: Círculo de Bellas Artes.

CAmacho Rojo, J. M. (1990). Apuntes para un estudio de la tradición clásica en la obra de Federico García Lorca. Florentia iliberritana: Revista de estudios de antigüedad clásica, 1, 55-73. 
Carmona VÁzquez, A. (2003). Coincidencias de lo trágico entre Eurípides y Federico García Lorca. Alcañiz: Instituto de Estudios Humanísticos; Madrid: Ediciones del Laberinto; CSIC.

CRISTÓBAL LóPEZ, V. (1993). Imágenes lorquianas de cuño clásico: metonimias y metáforas mitológicas. En J. M. MAeStre MAestre y J. PASCUAL BoreA (Eds.), Humanismo y pervivencia del mundo clásico: actas del I Simposio sobre Humanismo y pervivencia del mundo clásico, (Alcañiz, 8 al 11 de mayo de 1990) (pp. 377-388). Teruel: Instituto de Estudios Turolenses; Universidad de Cádiz: Servicio de Publicaciones.

GarcíA-PosadA, M. (Ed.) (2004). Federico García Lorca. Teatro completo II. Barcelona: Debolsillo. García-Posada, M. (Ed.) (2008a). Federico García Lorca. Obra completa I. Poesía, 1. (3 ${ }^{\mathrm{a}}$ ed.) Madrid: Akal.

García-Posada, M. (Ed.) (2008b). Federico García Lorca. Obra completa II. Poesía, 2. (3 ${ }^{\mathrm{a}}$ ed.) Madrid: Akal.

García-Posada, M. (Ed.) (2008c). Federico García Lorca. Obra completa III. Teatro, 1. (2 ${ }^{\mathrm{a}}$ ed.) Madrid: Akal.

García-Posada, M. (Ed.) (2008d). Federico García Lorca. Obra completa IV. Teatro, 2. (2a ed.) Madrid: Akal.

González Ruz, G., y Porres Caballero, S. (2012). Los sátiros o silenos. En A. Bernabé Pajares y J. PÉREZ De Tudela (Eds.), Seres híbridos en la mitología griega (pp. 227-270). Madrid: Círculo de Bellas Artes.

GONZÁlez TERrizA, A. A. (2015). La dulce mano que acaricia y mata: figuras siniestras femeninas en el mundo infantil grecolatino. Tesis doctoral UNED. Madrid.

GRAVES, R. (1955). The Greek Myths I. Edinburgh: Penguin Books.

GraZiosi, B., y HAubOLD, J. (Eds.) (2010). Homer: Iliad. Book VI. Cambridge: Cambridge University Press.

GRIMAL, P. (2010). Diccionario de mitología griega y romana. Barcelona: Paidós.

Hugo, V. (1976). Quatrevingt-treize. Paris: Garnier-Flammarion.

IRIARTE, A. (1990). Las redes del enigma. Voces femeninas en el pensamiento griego. Madrid: Taurus. MARTínez NADAL, R. (1986). Ecos clásicos en la obra de Federico García Lorca y Luis Cernuda. En I. RodríGueZ Alfageme y A. BRAvo García (Eds.), Tradición clásica y siglo XX (pp. 37-55), Madrid: Coloquio.

Murray, A. T. (Ed.) (1967). Homer: The Iliad 2, Books XIII-XXIV. Cambridge: Harvard University Press; London: Heinemann.

RodRíGUEZ BLANCO, M. E. (2011). Mujeres monstruo y monstruos de mujer en la mitología griega. En R. LÓPEZ GREGORIS y L. UNCETA GÓMEZ (Eds.), Ideas de mujer: Facetas de lo femenino en la Antigüedad (pp. 65-91). Alicante: Publicaciones Universidad de Alicante.

Román Román, I. (2003). Los mitos clásicos en la poesía de Federico García Lorca. Anuario de Estudios Filológicos, 26, 387-405. 
TARRANT, R. (Ed.) (2004). P. Ovidi Nasonis Metamorphoses. Oxonii: E Typographeo Clarendoniano; New York: Oxford University Press.

TuREL, S. (1986). La "quimera" de García Lorca: expresión surrealista de un mito. Cuadernos Hispanoamericanos. Homenaje a García Lorca, 1 (433-434), 351-358.

West, M. L. (Ed.) (1966). Hesiod: Theogony. Edited, with prolegomena and commentary. Oxford: Clarendon Press. 